The American Journal of Chinese Medicine, Vol. 34, No. 1, 125-135

(C) 2006 World Scientific Publishing Company

Institute for Advanced Research in Asian Science and Medicine

\title{
Antiproliferative and Apoptotic Effects of Tetrandrine on Different Human Hepatoma Cell Lines
}

\author{
Lean Teik Ng \\ Department of Biotechnology, Tajen University, Pingtung, Taiwan \\ Lien-Chai Chiang, ${ }^{*}$ Yu-Tseng Lin $^{\dagger}$ and Chun-Ching $\operatorname{Lin}^{\dagger}$ \\ ${ }^{*}$ Graduate Institute of Medicine and ${ }^{\dagger}$ Graduate Institute of Natural Products, College of Pharmacy \\ Kaohsiung Medical University, Kaohsiung, Taiwan
}

\begin{abstract}
Tetrandrine (TET), a bis-benzylisoquinoline alkaloid isolated from the dried root of Hang-Fang-Chi (Stephania tetrandra S. Moore), is well known to possess activities including antioxidant, anti-inflammation, anti-fibrotic and anticancer. It is used clinically to treat hypertension and silicosis. In the present study, the anti-proliferative and apoptotic effects of TET were evaluated on three different hepatoma cell lines, namely Hep G2, PLC/PRF/5 and Hep 3B. Using XTT assay, results showed that the $\mathrm{IC}_{50}$ values of TET were $4.35 \mu \mathrm{M}$ for Hep G2, $9.44 \mu \mathrm{M}$ for PLC/PRF/5 and $10.41 \mu \mathrm{M}$ for Hep 3B cells. The $\mathrm{CC}_{50}$ of TET against BNL-CL. 2 mouse normal liver cells was $31.12 \mu \mathrm{M}$. Interestingly, TET exhibited a lower $\mathrm{IC}_{50}$ value and better selectivity against Hep G2 and PLC/PRF/5 cells than cisplatin. Microscopic observation study, DNA fragmentation assay and flow cytometric analysis further supported apoptotic effect of TET on both PLC/PRF/5 and Hep 3B cells. The cell cycle of PLC/PRF/5 treated with TET appeared to arrest at G2/M phase in a dose-dependent manner, whereas no effect was noted on the cell cycle of Hep 3B cells. The present study concludes that TET exhibited anti-proliferative effect on Hep G2, PLC/PRF/5 and Hep 3B cells in a dose-dependent manner. TET also possesses a lower $\mathrm{IC}_{50}$ and better SI value than cisplatin against Hep G2 and PLC/PRF/5 cells. The effect of TET on cell cycle progression was found to vary with the type of hepatoma cells, suggesting the genetic make-up of the cells play an important role in the response to drug treatment.
\end{abstract}

Keywords: Tetrandrine; Hepatoma; Apoptosis; Stephania tetrandra.

Correspondence to: Dr. Chun-Ching Lin, Graduate Institute of Natural Products, College of Pharmacy, Kaohsiung Medical University, 100 Shih-Chuan 1st Road, Kaohsiung 807, Taiwan. Tel: (+886) 7-312-1101 (ext. 2122), Fax: (+886) 7-313-5215, E-mail: aalin@ms24.hinet.net 


\section{Introduction}

Tetrandrine (TET) (Fig. 1) is a bis-benzylisoquinoline alkaloid isolated from the root of Stephania tetrandra S. Moore (Menispermaceae), which is known as Hang-FangChi in Chinese. Its plant material has been used in traditional Chinese medicine as an anti-rheumatic, anti-inflammatory and anti-hypertensive agent (Shen et al., 2001). TET was reported to possess a very broad spectrum of pharmacological actions; for example plasma glucose lowering (Chen et al., 2004), anti-inflammatory (Li et al., 1989), immunosuppressive (Li et al., 1989) and free radical scavenging activities (Cao, 1996). It also exhibited cytotoxic effect on various types of cancer cells, including A549 (Lee et al., 2002), Hep G2 (Yoo et al., 2002), U937 (Lai et al., 1998; Jang et al., 2004), MCF-7 (Wang et al., 2002), HL-60 (Dong et al., 1997), HeLa (The et al., 1991) and T-HSC/Cl-6 (Zhao et al., 2004) cells. However, it has never been tested on hepatoma PLC/PRF/5 and Hep 3B cells.

In rat model of silicosis, TET was found to possess anti-fibrotic activity. It effectively blocked the ability of quartz to stimulate oxidant release from pulmonary phagocytes, and protected hepatocytes against $\mathrm{CCl}_{4}$ injury (Chen et al., 1996). Clinically, TET has been used as a drug for treating hypertension and silicosis (Qian, 2002; Xie et al., 2002).

Hepatocellular carcinoma (HCC) is one of the most prevalent malignant diseases in China, Taiwan, Korea and Sub-Africa (Chen et al., 1996; He et al., 1996). The major cause of HCC widespread in Taiwan is known to result from hepatitis B virus (HBV) infection (Harris, 1990). Most patients diagnosed with HCC have low recovery rates, and conventional and modified therapies currently available are rarely beneficial (Harris, 1990; Okuda, 1992). To evaluate the potential benefit of TET on treatment of hepatoma, three different HCC cell lines (Table 1), namely Hep G2, PLC/PRF5 and Hep 3B were tested in this study.

Hep G2 and Hep 3B cells are highly differentiated cells (Simon et al., 1982) whereas PLC/PRF/5 is less divided but highly migrated hepatoma cells (Zvibel et al., 1991). They behave functionally as highly differentiated liver parenchymal cells and are karyologically distinguishable from PLC/PRF/5, both by the presence of trisomy 6 (pter leads to q14) and with one of the long arm of chromosome 15 is $15 \mathrm{q}+$ (Simon et al., 1982). Hep G2 and Hep 3B cells, not PLC/PRF/5 cells, secrete IGF carrier protein (Moses et al., 1983) and produce $\alpha$-2-plasmin inhibitor ( $\alpha-\mathrm{PI}$ ), a physiological inhibitor (Saito et al., 1982).

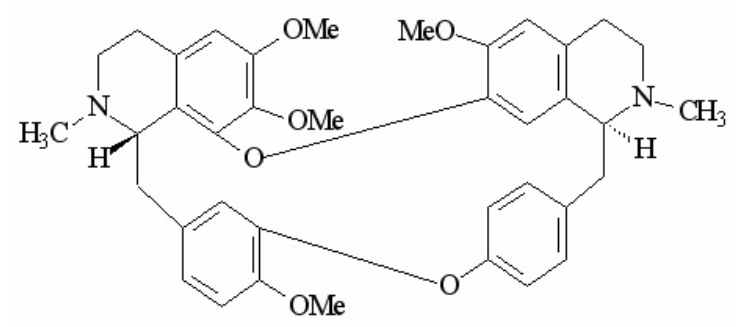

Figure 1. The structure of tetrandrine. 
Table 1. Characteristics of Hep G2, Hep 3B and PLC/PRF/5 Cell Lines

\begin{tabular}{lccccc}
\hline Cell Lines & HBV-DNA $^{*}$ & p53 & Fas Receptor & RB $^{\dagger}$ & Histology \\
\hline Hep G2 & - & Normal & Normal & + & Hepatoblastoma \\
PLC/PRF/5 & + & Mutation & No function & + & Hepatocellular carcinoma \\
Hep 3B & + & Deletion & - & - & Hepatocellular carcinoma \\
\hline
\end{tabular}

*Hepatitis B virus-DNA. ${ }^{\dagger}$ Retinoblastoma.

In this study, our objective was to examine the effects of TET on cell growth and apoptosis in different human hepatoma Hep G2, Hep 3B and PLC/PRF/5 cells.

\section{Materials and Methods}

\section{Chemicals}

Tetrandrine, with purity greater than 98\%, was purchased from Fluka (St. Gallen, Switzerland). It was dissolved in dimehylsulfoxide (DMSO) to prepare a stock solution of $3.2 \mathrm{mM}$. For each experiment, it was diluted further with distilled water to desired concentrations $(4,8,16$ and $32 \mu \mathrm{M})$. The final DMSO concentration was about $0.1 \%$. Cisplatin (a commercial anticancer drug), propidium iodide, bovine pancreatic proteinase A, HistoPaque ${ }^{\circledR}-1077$ solution and sodium salt of 2,3-bis[2-methoxy-4-nitro-5-sulfophenyl]-2Htetrazolium-5-carboxanilide (XTT) kits were obtained from Sigma Aldrich Co. (St. Louis, MO, USA). Proteinase K was purchased from Roche Diagnostics (Gmbh, Mannheim, Germany). The Bio- $100^{\mathrm{TM}}$ DNA Ladder marker was obtained from PROtech Technology Enterprise Co. (Taipei, Taiwan). All other chemicals used were of analytical grade.

\section{Cell Culture}

The human hepatoma PLC/PRF/5 (ATCC CRL8024), Hep 3B (ATCC HB8064) and Hep G2 (ATCC HB 8065) cells and BNL-CL.2 mouse normal liver (ATCC TIB-73) cells were obtained from the American Type Culture Collection (Rockville, MD, USA). The cells were cultured in Dulbecco's modified Eagle's medium (DMEM; Gibco, Grand Island, NY, USA), supplemented with $10 \%$ fetal calf serum (FCS), 100 units penicillin G, $100 \mu \mathrm{g} / \mathrm{ml}$ streptomycin and $0.25 \mu \mathrm{g} / \mathrm{ml}$ amphotericin B (Gibco, Grand Island, NY, USA) in an incubator with humidified air at $37^{\circ} \mathrm{C}$ with $5 \% \mathrm{CO}_{2}$.

\section{Antiproliferative Effect Assay}

The effect of TET on cell proliferation was determined by XTT colorimetric assay (Roehm et al., 1991). The cells $\left(1 \times 10^{4} /\right.$ well $)$ were plated onto 96 -well microplates, each well received $100 \mu \mathrm{L}$ DMEM medium containing different concentrations of TET $(4,8,16$ and $32 \mu \mathrm{M})$. They were then incubated for 6, 12, 24, 36 and 48 hours. After incubation, the medium was replaced with $100 \mu \mathrm{l}$ of non-FCS DMEM per well. The mixture of $100 \mu \mathrm{l}$ 
phenazine methosulfate (PMS; electron-coupling reagent; $0.383 \mathrm{mg} / \mathrm{ml}$ ) and $50 \mu \mathrm{l}$ of XTT were then added to each well. The plate was incubated for another 4 hours. The absorbance of sample was determined by an ELISA reader (Multiskan EX ${ }^{\circledR}$, Labsystems, Helsinki, Finland) at a test wavelength of $492 \mathrm{~nm}$ and a reference wavelength of $690 \mathrm{~nm}$.

\section{Morphological Observation}

Cells were treated with different doses of TET $(8,16$ and $32 \mu \mathrm{M})$ at various time periods. They were then fixed and stained with Liu's solution (Liu, 1970). The morphological changes of cells were observed under fluorescent microscopy (Zeiss Axioskop, Mikron Instruments, NY, USA).

\section{DNA Fragmentation Analysis}

The DNA fragmentation analysis was performed as previously described (Chen et al., 2001). In brief, vehicle control (0.1\% DMSO) and TET-treated groups were collected in a $15 \mathrm{ml}$ tube and centrifuged at $200 \times \mathrm{g}$ for 5 minutes. They were then transferred to an Eppendorfmicrotube and precipitated at $200 \times \mathrm{g}$ for 5 minutes. Each pellet was resuspended in $195 \mu \mathrm{l}$ lysis-buffer [every $740 \mu \mathrm{l}$ containing $37 \mu \mathrm{l}$ of $1 \mathrm{M}$ Tris $(\mathrm{pH} 8.0), 14.8 \mu \mathrm{l}$ of 0.5M EDTA, $10 \mu \mathrm{l}$ of $75 \%$ sodium lauryl sarcosine, $678.2 \mu \mathrm{l}$ of $\mathrm{H}_{2} \mathrm{O}$ ]. Five $\mu \mathrm{l}$ of $10 \mathrm{mg} / \mathrm{ml}$ proteinase-K was then added at the same time. After thorough mixing, the mixture was maintained at $50^{\circ} \mathrm{C}$ water-bath overnight, followed by the addition of $10 \mu \mathrm{l}$ of $10 \mu \mathrm{g} / \mathrm{ml}$ RNase-A and the mixture was further incubated at $50^{\circ} \mathrm{C}$ for 1 hour. DNA was isolated after phenolchloroform extraction and ethanol precipitation, followed by resuspension in PBS. The DNA was analyzed on a $2 \%$ agarose gel, stained with ethidium bromide, and detected under $254 \mathrm{~nm}$ UV illuminations. The Bio- $100^{\mathrm{TM}}$ DNA Ladder marker was used as reference.

\section{Cell Cycle Analysis}

The analysis of cell cycle distribution was conducted according to the previously described method (Kuo and Lin, 2003). In brief, cells $\left(8 \times 10^{5}\right.$ cells/well) were seeded onto a six-well plate. After treating with various concentrations of TET $(8,16$ and $32 \mu \mathrm{M})$ for 12 and 24 hours, cells were washed with PBS and then fixed with $70 \%$ ethanol. Cells were washed with PBS again and incubated further with $25 \mu \mathrm{l}$ of $0.5 \%$ triton X-100 and $10 \mu \mathrm{l}$ of RNase-A $(10 \mu \mathrm{g} / \mathrm{ml})$ in $565 \mu \mathrm{PBS}$ at $37^{\circ} \mathrm{C}$ for 1 hour. After propidium iodide staining, cells were analyzed by flow cytometry. The distribution of cell cycle was analyzed by MultiCycle AV (Phoenix Flow Systems, Inc. San Diego, California, USA).

\section{Statistical Analysis}

Data are presented as means \pm SD of three independent experiments and were evaluated by one way analysis of variance (ANOVA) using the Statistical Analysis System (SAS 
Institute, Cary, NC, USA). Unpaired Student's t-test was used to compare differences between control and test samples. Differences were considered significant when $\mathrm{p}<0.05$.

\section{Results}

TET Inhibited the Proliferation of Hep G2, PLC/PRF/5 and Hep 3B Cells

Table 2 showed the growth inhibitory effects of TET on Hep G2, PLC/PRF/5 and Hep 3B cells. Results indicated that TET exhibited a lower $\mathrm{IC}_{50}$ value than cisplatin against PLC/ PRF/5, Hep 3B and Hep G2 cells. However, a small difference between the $\mathrm{IC}_{50}$ of TET and cisplatin was noted on Hep 3B cells. The SI of TET was superior to that of cisplatin against PLC/PRF/5 and Hep G2 but was inferior to cisplatin on the Hep 3B cells. Compared with 5-FU, TET possessed a superior SI value on Hep G2 but not on the PLC/PRF/5 and Hep 3B cells. Consistent with previous studies, TET significantly inhibited the cell growth on Hep G2 cells (Kuo and Lin, 2003). TET also exhibited an anti-proliferative effect on $\mathrm{PLC} / \mathrm{PRF} / 5$ and Hep 3B cells in a dose-dependent manner.

\section{TET Induced Morphological Changes in PLC/PRF/5 and Hep $3 B$ Cells}

Figure 2 indicated that TET treatment resulted in a typical apoptotic appearance on PLC/ $\mathrm{PRF} / 5$ and Hep 3B cells, such as chromatin condensation. A normal appearance other than apoptotic cells was also noted on the TET-treated group.

\section{Effects of TET on DNA Fragmentation}

Results showed that the level of DNA fragmentation became more prominent with increasing time and doses (Fig. 3). This observation further supported the apoptotic changes appearing in the microscopic results as mentioned above. The low molecular DNA fragments (around $180 \mathrm{bp}$ ) could be easily detected on the rows of higher dose and at the later time-point. This appearance is a typical characteristic of apoptosis.

Table 2. Anti-proliferative Activity of Tetrandrine (TET) Against Three Different Human Hepatoma Cells and BNL-CL.2 Mouse Normal Liver Cells

\begin{tabular}{lccccccc}
\hline & \multicolumn{7}{c}{ Cell Lines } \\
\cline { 2 - 8 } & BNL-CL.2 & \multicolumn{7}{c}{ Hep G2 } & \multicolumn{2}{c}{ PRC/PRF/5 } & Hep 3B \\
\hline Compounds & $\mathrm{CC}_{50}{ }^{*}$ & $\mathrm{IC}_{50}{ }^{\dagger}$ & $\mathrm{SI}^{+}$ & $\mathrm{IC}_{50}$ & $\mathrm{SI}$ & $\mathrm{IC}_{50}$ & $\mathrm{SI}$ \\
Tetrandrine & 31.12 & 4.35 & 7.15 & 9.44 & 3.30 & 10.41 & 2.99 \\
Cisplatin & 162.25 & 142.82 & 1.14 & 94.34 & 1.72 & 28.12 & 5.77 \\
Fluorouracil & 533.13 & 140.99 & 3.78 & 5.07 & 105.15 & 95.63 & 5.57 \\
\hline
\end{tabular}

${ }^{*} \mathrm{CC}_{50}$ is the concentration $(\mu \mathrm{M})$ that reduces the growth of BNL-CL.2 mouse normal liver cells by $50 \%$. ${ }^{\dagger} \mathrm{IC}_{50}$ is the inhibitory concentration $(\mu \mathrm{M})$ that reduces cellular growth or viability of cells by $50 \%$. ${ }^{\ddagger}$ Selectivity Index $(\mathrm{SI})=\mathrm{CC}_{50} / \mathrm{IC}_{50}$. 
A

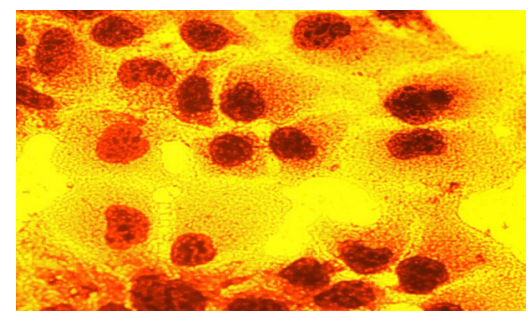

$\mathrm{B}$

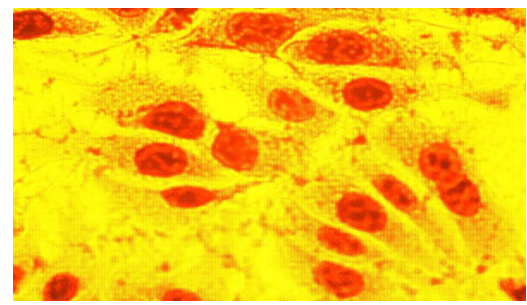

$\mathrm{C}$

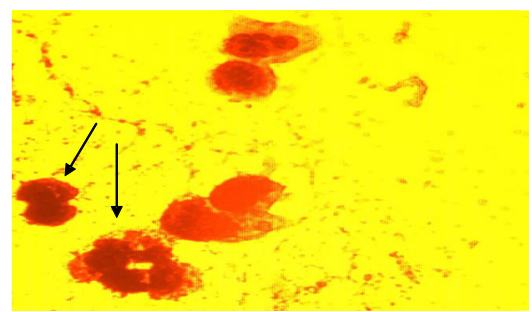

$\mathrm{D}$

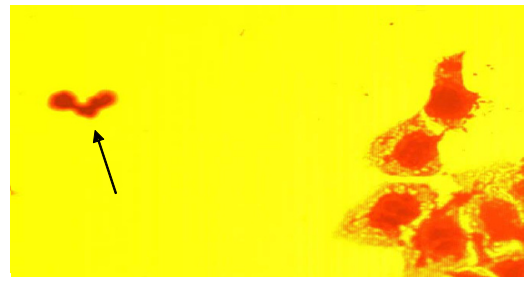

Figure 2. Microscopic appearance of Hep 3B and PLC/PRF/5 cells. (A) Hep 3B cells without TET. (B) PLC/ PRF/5 cells without TET. (C) and (D) are Hep 3B and PLC/PRF/5 cells treated with TET $16 \mu \mathrm{M}$ for 24 hours, respectively. Arrows indicate morphologically apoptotic changes, including condensed and fragmented nuclei, and apoptotic bodies.

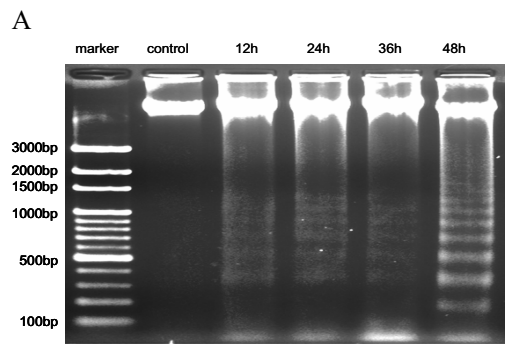

C

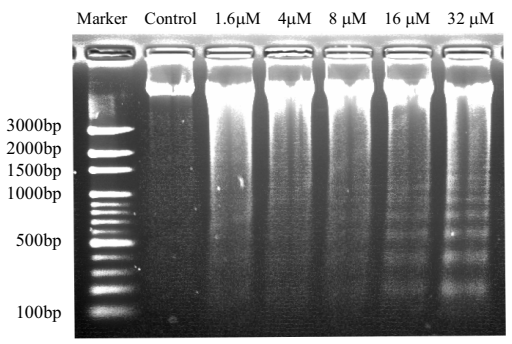

B

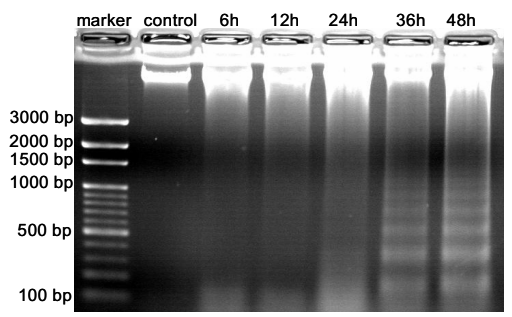

$\mathrm{D}$

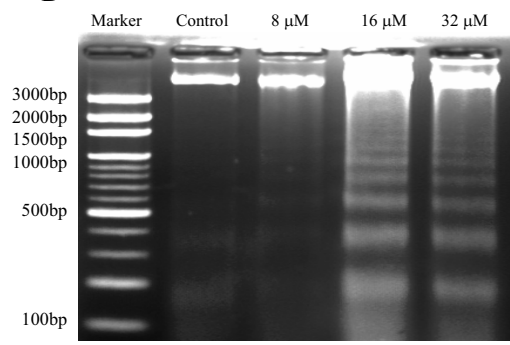

Figure 3. DNA fragmentation of PLC/PRF/5 and Hep 3B cells induced by tetrandrine (TET). DNA fragmentation of PLC/PRF/5 (A) and Hep 3B (B) cells after treating with $16 \mu \mathrm{M}$ TET for various time periods. DNA fragmentation of PLC/PRF/5 (C) and Hep 3B (D) cells after treating with various concentrations of TET for 36 hours. 


\section{Effects of TET on Cell Cycle in PLC/PRF/5 and Hep 3B Cells}

Table 3 showed the effects of various concentrations (8, 16 and $32 \mu \mathrm{M})$ of TET on PLC/ $\mathrm{PRF} / 5$ and Hep 3B cells. Compared with the untreated cells, the percentage of G2/M phase of PLC/PRF/5's cell cycle appeared to increase in a dose-dependent manner, whereas a trend of decrease was noted in the S phase. When the PLC/PRF/5 cells were treated with TET for a period longer than 24 hours, no obvious cell cycle arrest was noted.

In the experiment with Hep 3B cells, a decrease in the $G_{0} / G 1$ and $S$ phases was noted with increasing concentrations of TET. However, there was no obvious cell arrest occurring at the G2/M phase. When the Hep 3B cells were treated with different concentrations (8, 16 and $32 \mu \mathrm{M}$ ) of TET for a period longer than 24 hours, cell cycle arrest was not noted at any phases of the cell cycle.

In contrast with the observation noted on the Hep G2 cells (Kuo and Lin, 2003), TET significantly increased the population of $\mathrm{G}_{0} / \mathrm{G} 1$ phase in a dose-dependent manner, suggesting TET effectively blocked cell cycle progression in the G1 phase.

\section{Discussion}

Previous studies have shown that TET was effective in inhibiting the proliferation of several cancer cell lines, including A549 (Lee et al., 2002), Hep G2 (Yoo et al., 2002), U937 (Lai et al., 1998; Jang et al., 2004), MCF-7 (Wang et al., 2002), HL-60 (Dong

Table 3. Effect of TET on the Cell Cycle of PLC/PRF/5 and Hep 3B Cells1.5

(A) PLC/PRF/5

\begin{tabular}{|c|c|c|c|c|c|}
\hline \multirow[b]{3}{*}{ Phase } & \multicolumn{5}{|c|}{$\%$ Distribution } \\
\hline & \multicolumn{2}{|c|}{ Control } & \multicolumn{3}{|c|}{ TET $(\mu \mathrm{g} / \mathrm{ml})$} \\
\hline & Medium & $0.1 \%$ DMSO & 5 & 10 & 20 \\
\hline G1 & $56.1 \pm 1.0$ & $52.8 \pm 1.3$ & $51.8 \pm 1.6$ & $53.0 \pm 0.7$ & $53.6 \pm 1.3$ \\
\hline$S^{*}$ & $27.0 \pm 1.9$ & $29.9 \pm 2.7$ & $21.7 \pm 0.8$ & $16.9 \pm 0.9$ & $7.8 \pm 1.8$ \\
\hline $\mathrm{G} 2 / \mathrm{M}^{*}$ & $15.4 \pm 1.1$ & $12.5 \pm 2.5$ & $18.9 \pm 2.0$ & $21.1 \pm 0.2$ & $28.1 \pm 0.7$ \\
\hline
\end{tabular}

(B) Hep 3B

\begin{tabular}{|c|c|c|c|c|c|}
\hline \multirow[b]{3}{*}{ Phase } & \multicolumn{5}{|c|}{$\%$ Distribution } \\
\hline & \multicolumn{2}{|c|}{ Control } & & \multicolumn{2}{|c|}{ TET $(\mu \mathrm{g} / \mathrm{ml})$} \\
\hline & Medium & 0.1\% DMSO & 5 & 10 & 20 \\
\hline $\mathrm{G} 1^{*}$ & $53.1 \pm 3.8$ & $54.1 \pm 2.0$ & $53.0 \pm 1.2$ & $46.5 \pm 4.2$ & $40.3 \pm 2.6$ \\
\hline$S^{*}$ & $26.0 \pm 5.6$ & $24.0 \pm 0.8$ & $23.7 \pm 2.9$ & $18.9 \pm 5.1$ & $14.1 \pm 4.3$ \\
\hline $\mathrm{G} 2 / \mathrm{M}$ & $15.1 \pm 1.9$ & $18.4 \pm 2.8$ & $18.8 \pm 2.3$ & $19.8 \pm 5.3$ & $17.8 \pm 4.6$ \\
\hline
\end{tabular}

The pattern of cell cycle of (A) PLC/PRF/5 and (B) Hep 3B cells after treating with the medium, $0.1 \%$ DMSO vehicle, and 5, 10 and $20 \mu \mathrm{g} / \mathrm{ml}$ TET for 12 hours. Data are presented as means \pm SD of three independent experiments. ${ }^{*}$ The percentage of $\mathrm{G} 1$ or $\mathrm{S}$ or $\mathrm{G} 2 / \mathrm{M}$ phase was significantly $(\mathrm{p}<0.05)$ changed in a dose-dependent manner as analyzed by ANOVA. 
et al., 1997), HeLa (The et al., 1991), T-HSC/Cl-6 (Zhao et al., 2004) and neuro 2a mouse neuroblastoma (Jin et al., 2002) cells. In this study, TET showed growth inhibitory effect and cell apoptosis induction on Hep G2, PLC/PRF/5 and Hep 3B cells. TET was found to possess a lower $\mathrm{IC}_{50}$ value than cisplatin against Hep G2, PLC/PRF/5 and Hep 3B cells. Compared with 5 -FU, although TET possesses a lower $\mathrm{IC}_{50}$ value against $\mathrm{Hep} 3 \mathrm{~B}$ cell lines, its SI values were inferior to this drug. This observation suggests that the difference in genetic make-up of hepatoma cells would have contributed to the difference in response to the drugs.

TET at concentrations 5 80 $\mu \mathrm{M}$ was shown to decrease collagen and hyaluronic acid synthesis in human lung fibroblast HLF cells, and with no obvious toxic effect on these cells at 5 20 $\mu \mathrm{M}$ (Liu et al., 1995). This implies that TET could be a potential good source of agent for treating liver cancer. In clinical study (Li, 1981), the therapeutic dose of TET for treatment of silicosis was around $10 \mu \mathrm{m}$, which is close to the $\mathrm{IC}_{50}$ concentration against Hep G2 $\left(\mathrm{IC}_{50}=4.35 \mu \mathrm{M} ; \mathrm{SI}=7.15\right), \mathrm{PLC} / \mathrm{PRF} / 5\left(\mathrm{IC}_{50}=9.44 \mu \mathrm{M} ; \mathrm{SI}=3.30\right)$ and Hep 3B $\left(\mathrm{IC}_{50}=10.4 \mu \mathrm{M} ; \mathrm{SI}=2.99\right)$ cells.

Results of the XTT analysis showed that carrier of HBV-DNA cells, PLC/PRF/5 and Hep 3B, exhibited a significant $(\mathrm{p}<0.05)$ lesser response towards TET than Hep G2 cells. This finding was consistent with results previously reported, where plant extracts were found to be more effective against non-HBV-related cell lines (ex. Hep G2) than against HBV-related cell lines (ex. PLC/PRF/5, Hep B2) (Chen et al., 1990; Bressac et al., 1991). $\mathrm{CC}_{50}$ analysis showed that, compared to the BNL-CL.2 mouse normal liver cells, TET demonstrated a greater cytoxicity on human lymphocytes (Ho et al., 1999; Lai et al., 2001). Previous studies have shown that the cytoxicity of TET varies with different species. For example, the hepatoxicity and nephrotoxicity were found to be more obvious in rhesus monkey than in beagle dogs (Gralla et al., 1974).

In the DNA fragmentation study, the density of DNA ladder appeared to decrease as concentration of TET reaching $32 \mu \mathrm{M}$. This could be explained by the acute toxicity at high concentration of TET, thus causing a decrease in the DNA ladder.

It was well known that cell cycle arrest and apoptosis play important roles in cell life. After TET treatment, cell cycle arrest was noted at G2/M phase in a dose-dependent manner in the PLC/PRF/5 cells. However, this event was not noted in the Hep 3B cells, which is lacking of dominant RB gene, although the ratio of $\mathrm{G} 1$ or $\mathrm{S}$ phase decreases as concentration of TET increases. It was known that when the RB protein is subjected to low density phosphorylation, it will react with transcription factor E2F and lead to the inhibition of its release. This event consequently suppresses the cell cycle progress from $\mathrm{G}_{0} / \mathrm{G} 1$ to $\mathrm{S}$ phase (Johnson and Schneider-Broussard, 1998). Because of the lacking in the RB gene, drugs are not effective in causing cell cycle arrest in the Hep 3B cells. It was shown that p53 play an important role in TET-induced anti-proliferative activity in Hep G2 cells (Kuo and Lin, 2003). Induction of p53 by TET not only causes Hep G2 cell arrest, but also triggers apoptosis. However, it is unknown if p53 expression plays a similar role in PLC/PRF/5 and Hep 3B cells.

In conclusion, the present study demonstrates that TET possesses potent antiproliferative activity on Hep G2, PLC/PRF/5 and Hep 3B cells. The effect of TET on 
proliferation of these hepatoma cells appeared to be dose-dependent. Although TETinduced cell apoptosis in both PLC/PRF/5 and Hep 3B cells, its mechanism of action(s) remains unclear. Flow cytometric analysis indicate that the effect of TET on cell cycle progression varies with the type of hepatoma cells, suggesting the genetic make-up of the cells play an important role in the response to drug treatment.

\section{References}

Bressac, B., M. Kew, J. Wands and M. Ozturk. Selective G to T mutations of p53 gene in hepatocellular carcinoma from southern Africa. Nature 350: 429-431, 1991.

Cao, Z.F. Scavenging effect of tetrandrine of active oxygen radicals. Planta Med. 62: 413-414, 1996.

Chen, P.L., Y.M. Chen, R. Bookstein and W.H. Lee. Genetic mechanisms of tumor suppression by the human $p 53$ gene. Science 250: 1576-1580, 1990.

Chen, W.C., S. Hayakawa, T. Yamamoto, L.W. Huang, I.M. Liu and J.T. Cheng. The plasma glucose lowering action of tetrandrine in strptozotocin-induced diabetic rats. J. Pharm. Pharmacol. 56: 643-648, 2004.

Chen, X., Z. Liu and Z. Ai. Antineoplastic mechanism of Octreotide action in human hepatoma. Chin. Med. J. 114: 1167-1170, 2001.

Chen, X.H., Y.M. Hu and Y.Q. Liao. Protective effects of tetrandrine on $\mathrm{CCl}_{4}$-injured hepatocytes. Zhongguo Yao Li Xue Bao 17: 348-350, 1996.

Dong, Y., M.M. Yang and C.Y. Kwan. In vitro inhibition of proliferation of HL-60 cells by tetrandrine and coriolus versicolor peptide derived from Chinese medicinal herbs. Life Sci. 60: 135-140, 1997.

Gralla, E.J., G.L. Coleman and A.M. Jonas. Toxicology studies with d-tetradrine (NSC-77037), a plant alkaloid with vascular and lymphotoxic effects in dogs and monkeys. Cancer Chemother. Rep. 35: 79-85, 1974.

Harris, C.C. Hepatocellular carcinogenesis: recent advances and speculations. Cancer Cells 2: 146-148, 1990.

He, Y., K. Xu, Q. Zhang, W. Dai, Z. Xu and B. Liu. Inhibitory effect of tetrandrine on collagen synthesis of experimental hepatic fibrosis in rats. Zhongguo Zhong Yao Za Zhi 21: 177-179, 1996.

Ho, L.J., D.M. Chang, T.C. Lee, M.L. Chang and J.H. Lai. Plant alkaloid tetrandrine downregulates protein kinase C-dependent signaling pathways in T cells. Eur. J. Pharmacol. 367: 389-398, 1999.

Jang, B.C., K.J. Lim, J.H. Paik, J.W. Cho, W.K. Back, M.H. Suh, J.B. Park, T.K. Kwon, J.W. Park, S.P. Kim, D.H. Shin, D.K. Song, J.H. Bae, K.C. Min and S.L. Suh. Tetrandrine-induced apoptosis is mediated by activation of caspases and PKC-delta in U937 cells. Biochem. Pharmacol. 67: 1819-1829, 2004.

Jin, Q., C. Kang, Y. Soh, N.W. Sohn, J. Lee, Y.H. Cho, H.H. Baik and I. Kang. Tetrandrine cytotoxicity and its dual effect on oxidative stress-induced apoptosis through modulating cellular redox states in neuro 2a mouse neuroblastoma cells. Life Sci. 71: 2053-2066, 2002.

Johnson, G.L. and R. Schneider-Broussard. Role of E2F in cell cycle control and cancer. Front Biosci. 3: 447-448, 1998.

Kuo, P.L. and C.C. Lin. Tetrandrine-induced cell cycle arrest and apoptosis in Hep G2 cells. Life Sci. 73: 243-252, 2003. 
Lai, J.H., L.J. Ho, K.C. Lu, D.M. Chang, M.F. Shaio and S.H. Han. Western and Chinese anti-rheumatic drug-induced $\mathrm{T}$ cell apoptotic DNA damage uses different caspase cascades and is independent of Fas/Fas ligand interaction. J. Immunol. 166: 6914-6924, 2001.

Lai, Y.L., Y.J. Chen, T.Y. Wu, S.Y. Wang, K.H. Chang, C.H. Chung and M.L. Chen. Induction of apotosis in human leukemic U937 cells by tetrandrine. Anticancer Drugs 9: 77-81, 1998.

Lee, J.H., G.H. Kang, K.C. Kim, K.M. Kim, D.L. Park, B.T. Choi, H.S. Kang, Y.T. Lee and Y.H. Choi. Tetrandrine-induced cell cycle arrest and apoptosis in A549 human lung carcinoma cells. Int. J. Oncol. 21: 1239-1244, 2002.

Li, Q.L. The therapeutic effect of tetrandrine on silicosis. Zhonghua Jie He He Hu Xi Xi Ji Bing Za Zhi 4: 321-323, 1981.

Li, S.Y., L.H. Ling, B.S. Teh, W.K. Seow and Y.H. Thong. Anti-inflammatory and immuno-suppressive properties of the bis-benzylisoquinolines: in vitro comparisons of tetrandrine and berbamine. Int. J. Immunopharmacol. 11: 395-401, 1989.

Liu, H.L., H.M. Lu, D.G. Li, Z.M. Jiang and F. Qi. Effects of tetrandrine and chlorpromazine on synthesis of collagen and hyaluronic acid in cultured human lung fibroblasts. Zhongguo Yao Li Хие Вао 16: 412-414, 1995.

Liu, W. A. simplified cytologic staining technique. Am. J. Clin. Pathol. 54: 767-768, 1970.

Moses, A.C., A.J. Freinkel, B.B. Knowles and D.P. Aden. Demonstration that human hepatoma cell line produces a specific insulin-like growth factor carrier protein. J. Clin. Endocrinol. Metab. 56: 1003-1008, 1983.

Okuda, K. Hepatocellular carcinoma: recent progress. Hepatology 15: 948-963, 1992.

Qian, J.Q. Cardiovascular pharmacological effects of bisbenzylisoquinoline alkaloid derivatives. Acta Pharmacol. Sin. 23: 1086-1092, 2002.

Roehm, N.W., G.H. Rodgers, S.M. Hatfield and A.L. Glasebrook. An improved colorimetric assay for cell proliferation and viability utilizing the tetrazolium salt XTT. J. Immunol. Methods 142: 257-265, 1991.

Saito, H., L.T. Goodnough, B.B. Knowles and D.P. Aden. Synthesis and secretion of alpha 2-plasmin inhibitor by established human liver cell lines. Proc. Natl. Acad. Sci. USA 79: 5684-5687, 1982.

Shen, Y.C., C.J. Chou, W.F. Chiou and C.F. Chen. Anti-inflammatory effects of the partially purified extract of radix Stephaniae tetrandrae: comparative studies of its active principles tetrandrine and fangchinoline on human polymorphonuclear leukocyte functions. Mol. Pharmacol. 60: 1083-1090, 2001.

Simon, D., D.P. Aden and B.B. Knowles. Chromosomes of human hepatoma cell lines. Int. J. Cancer 30: 27-33, 1982.

The, B.S., P. Chen, M.F. Lavin, W.K. Seow and Y.H. Thong. Demonstration of the induction of apoptosis (programmed cell death) by tetradrine, novel anti-inflammatory agent. Int. J. Immunopharmacol. 13: 117-126, 1991.

Wang, J.H., Z.G. Ye, A.X. Sun, B.Y. Xue, A.H. Liang, C.Y. Li and L. Wang. Reversal of anti-apoptotic action by tetrandrine in human breast carcinoma multidrug-resistant MCF-7 cells. Zhongguo Zhong Yao Za Zhi 27: 46-50, 2002.

Xie, Q.M., H.F. Tang, J.Q. Chen and R.L. Bian. Pharmacological actions of tetrandrine in inflammatory pulmonary diseases. Acta Pharmacol. Sin. 23: 1107-1113, 2002.

Yoo, S.M., S.H. Oh, S.J. Lee, B.W. Lee, W.G. Ko, C.K. Moon and B.H. Lee. Inhibition of proliferation and induction of apoptosis by tetrandrine in Hep G2 cells. J. Ethnopharmacol. 81: 225-226, 2002. 
Zhao, Y.Z., J.Y. Kim, E.J. Park, S.H. Lee, S.W. Woo, G. Ko and D.H. Sohn. Tetrandrine induces apoptosis in hepatic stellate cells. Phytother. Res. 18: 306-309, 2004.

Zvibel, I., E. Halay and L.M. Reid. Heparin and hormonal regulation of mRNA synthesis and abundance of autocrine growth factors: relevance to clonal growth of tumors. Mol. Cell Biol. 11: 108-116, 1991. 